\title{
Join in the 'Upper-Class' student activities: UGM equestrian unit (unit berkuda UGM)
}

\author{
Arif Zuhdi Winarto \\ Cultural and Media Studies Universitas Gadjah Mada, Jl. Teknika Utara, Pogung, Sleman, \\ Yogyakarta, Indonesia, 55281 \\ e-mail: zuhdito@gmail.com
}

\begin{abstract}
Due to historical relationships with the military, royalty, landed gentry, and upper-class society, equestrian sport faces regular accusations of being elitist and exclusionary. How about in Indonesia? Equestrian clubs are now a lot of popping up and become popular in some of the major cities in this country. Even though looks similar, equestrian is totally different from traditional Indonesian horse race: 'Pacuan Kuda' that has already existed in this country. After the millennium, various discourses in the media about equestrian also forming the discourse of exclusionary in this country. Understand equestrian sport is important to consider how people participate in the sport and the different ways it is represented across countries, in this case, is in Indonesia. UGM Equestrian Unit, one of the oldest equestrian club in Yogyakarta, Indonesia, that consistently stands for UGM students since 1989. Many ways are done by this club in recruiting members every year and present themselves as a humble sport that can be followed by every UGM student in Yogyakarta, but the image of an 'upper-class' student activities appears even stronger year after year. Why did it happen?
\end{abstract}

\section{Keywords}

capital, distinction, equestrian, habitus, leisure, social class

\section{Introduction}

Yogyakarta (Java Island, Indonesia), is a city with a very large number of students so it is no wonder if various cultural characteristics exist in the city. Many immigrant students to study at various universities in Yogyakarta, so it called "Student City" or city for the student. The

Citation: Winarto, A. Z. (2018). Join in the 'Upper-Class' student activities: UGM equestrian unit (unit berkuda UGM). In M. Amini, M. Yusuf, \& V. I. Yulianto. (Eds.), UGM Digital Press Social Sciences and Humanities: Vol. 1. Proceeding of the 2nd International Conference on South East Asia Studies (pp. 13-18).

Published: October, 2018 middle-class students who are currently formed at UGM are a mixture of various elements. Some are middle-class who are middle-class, some are newly upgraded from lower to middle and fewer are those handed down by upper or upper-middle-class parents. The existence of the middle class, in this case, the students can not only be seen from the economic side only but in terms of culture can be seen that a middleclass lifestyle is also interesting to study. In the urban middle class is different from the middle class in the countryside because of differences in facilities and infrastructure so it also affects the activity and consumption in the community. Lifestyle becomes a way for the middle class to separate themselves or create distance from the lower classes in a society. The middle class constructs a level by creating a modern lifestyle through various means, including through 
consumption. By consuming the value of prestige, one can show social value, social status, and power on an object that is consumed thus causing social stratification. Lifestyle is not limited as a marker of identity but also to build a collective identity as a member of the middle class. Production of collective identity is done through lifestyle and membership of a class group expressed through a particular lifestyle presentation (Gerke, 2000, pp. 146-151).

Various activities they do to fill his spare time which aims to please his consumption desires. One of them is riding horse or equestrian. Equestrian requires higher levels of monetary investment and time (Fletcher and Dashper, 2012, pp. 1-3). According to Polley (1999, pp. 200-236), the main part of the sport's appeal of horses to the higher classes is their traditional image, and the opportunities are given by them to display the striking wealth. On the other hand, Bourdieu (1978, pp. 819-840) argues in his sports analysis, the ways played by different groups and display their physical culture are outer class markers. While the working class demands 'a sign of external power', the middle class emphasizes manners, health, and hygiene. In England, equestrian events have entered the summer Olympic program since 1912, but participation was limited to British military officers until 1952 (Dashper, 2012a, pp. 213-225). Due to historical ties with the military, nobility, nobility and upper-class society, equestrian sports face the usual accusations of being elitist and exclusive (Riedi, 2006, pp. 236-253). Although there are reports that 4.3 million people in the UK join (British Horse Industry Confederation, 2009), for many people, equestrianism retains the upper classes (Polley,1999, pp. 200-236). Moreover, although participation in equestrian riding is now much more evenly distributed across socioeconomic groups and now involves more women than men (British Equestrian Trade Association, 2006), sports history remains closely linked to upper-class masculinity (Dashper, 2012b, pp. 1109-1124). Previous analysis of media coverage of horsemen as a sport has revealed the class manifestation, sex and race of human spectacle and ambivalence and class obsession in the British media report on dressage at the London 2012 Olympics (Fletcher and Dr Dashper, 2012, pp. 1-17).

After the millennium, various media discourses on equestrian riding also form the exclusive discourse of the country. Some examples are the K-Pop wave of Korean "Gangnam Style" dance by 'PSY' in 2012 which shows the bourgeois Korean community custom of Gangnam. Korean pop star Psy finds 'Gangnam style' to mock the pretensions of Seoul's wealthy citizens. Most of the PSY video features riding the invisible horse through the streets of Seoul's Gangnam district. Actually, the video has triggered the dance "unseen horse." Gangnam means, it's like Korean Beverly Hills, "said PSY, aka Jae-Sang Park, In an interview with ABC News. For Indonesian celebrities 'Syahrini', 'Nabila Syakieb', and Indonesian supermodel 'Larasati' who followed professional riders, as well as religious discourse raised by popular Indonesian religious figure 'Abdullah Gymnastiar' / Aa Gym. He publishes a book on the benefits of horseback for Muslims and owns horse ranch and training and also says that Horse Riding is an effort that is in the process of teaching because it is indispensable in the struggle to uphold the religion of God (Gymnastiar, 2016, pp. 7).

Obviously, in Indonesia, it is the largest Muslim community in the world. Horse riding is a serious discourse that contributes to making this type of sport popular. Although it is so broad and not conical on the equestrian track, in fact, there are still many people who cannot distinguish between horse riding and equestrian sports, it's also interesting to check on other occasions. For many people, equestrianists retained the upper classes (Polley, 1999, pp. 200-236), but differed from the image that the UGM Equestrian Unit wanted to show targeting all classes. In the Convenience Class Theory, Veblen (2000[1899]., pp. 94) describes the relationship between social status and recreational choice. The modern form of sport represents a unique set of values, and thus, provides the means to differentiate between different social and social classes (Sugden and Tomlinson, 2000, pp. 311). However, on the other hand, the Equestrian Unit of UGM wants to provide a vehicle that can be followed by various classes.

The Equestrian Unit of Gadjah Mada University at the beginning of its existence is a sport of equestrian riding for veterinary students. In the course of its development, the interest of students and from outside is increasing. Therefore, in 1989 turned into an autonomous body in the form of student activities unit. Currently (2017) Equestrian Unit UGM has ten horses although not all are used for training. UGM Equestrian Unit seeks to change the perception that equestrian riding is an exclusive and expensive sport by bringing the motto "Horses for horseless" who try to introduce and popularize equestrian sport without differentiating the group (quoted from Profile of Equestrian Unit UGM in UKM Catalog UGM as well as blog and web developed by the club). At first, the club was only used by students from the veterinary faculty to care for horses as a tool of practice, but then many students from other faculties want to join. Because it has its own stable from the facility then the student manager of the cage adapting horse training as in Europe that is Equestrian, they often practice on campus grounds so that they are widely known and become popular, because it is popular than going into club members becomes cool. Signing into club 
members is not easy, lots of free time and expenses to be incurred. Only certain students can stay long in the club.

\section{Methods}

The approach used in this ethnographic study is a qualitative approach. Researchers choose temporarily to join the club and also participate when informants get together or practice. The study period is set between July 1 and May 1, 2016. Ethnographic research is limited to UGM Equestrian Unit members and spectators in the internal championships. This includes analyzing the online sources of member Instagram accounts and other online news articles. The concept of habitus, arena, and capital (Bourdieu, 1978, pp. 819-840) took a major position in this study.

\section{Different Types of Society, Standing Apart Together (Temporarily)}

In the Convenience Class Theory, Veblen (2000[1899], pp. 69-94) describes the relationship between social status and leisure choice. The modern form of sport represents a unique set of values, and thus, provides the means to differentiate between different social and social classes (Sugden and Tomlinson, 2000, pp. 311). Interestingly, however, participation in equestrian sports in the Equestrian Unit of UGM offers a more affordable cost then diverse Class groups have the opportunity to join the club. This results in heterogeneous club conditions. Heterogeneous in gender, age and also class. Each year the club recruits about 30 people who are set aside from about 100 applicants from various majors. From the data obtained from applicants in 2015 and 2016, the most majors are veterinary and engineering faculty as much as 30 $\%$, then social political science, and economics as much as $20 \%$, then medicine and social majors as much as $10 \%$, and Science majors as much as $5 \%$ and another major it is less than $5 \%$. The trend of female enthusiasts UGM Equestrian club also continues to rise. Although equestrian sports can be considered relatively progressive in relation to gender representation (this is the only sport where there is no segregation of sex and men and women compete with each other in an equivalent way), it maintains the image of tradition and conservatism. (Dashper, 2012c, pp. 213-225).

Pierre Bourdieu contributes significantly to social class studies in this paper as Gilbert and Gillett (2012, pp. 632-643), explain that equestrian sports are examples of production areas where 'sports products' is generated. Equestrian produce different types of horses depending on the discipline. For that is why the racehorse sport is different from the equestrian, the horse must be trained and castrated first in order to understand the command code performed by the rider. Is it possible that the clever horse that has been schooled becomes more valuable and different from the other horses? Unlike the Equestrian clubs in European countries, UGM Equestrian Unit has a number of horses that are used interchangeably to train by the members. Horse acts as a social agent participating in horse sporting events but also consumed products, Bourdieu (1984, pp. 130-232) explains that agents, human or non-human, and their social position are visible and can be seen in a field. Although the horse is owned by the club, the entire property of sport and horse care needs to be spent. Bourdieu concepts of the Field, cultural reproduction, capital (in various forms), and habitus are used in processing this paper.

At the beginning of UGM Equestrian Unit member recruitment, applicants pay a registration fee of Rp35.000 (2.5 \$) per person, then after receiving they are required to pay 150 thousand rupiahs (11.8 \$) for horse and feed care. But the trend in the arena is who loves horses most, they will definitely give a lot of money for horse care, he will give more members of the group who are also moving. Unwittingly, club members who are able to give a lot of money each month for the cost of horse care then he is more appreciated by club members. Bourdieu (1984, pp. 130-232) also says that the social position of an agent is influenced by the interaction between field rules (in this case equestrian sport) and its agents, capital and habitus. The concept of habitus determines the social position in the field. In the UGM riding club, this is interesting because the recruited members are not from the same background, so they also have different habitus. At least students from working class and middle-class family can join the club.

Bourdieu (1984, pp. 130-232) explains that classes are reproduced in and through the site in what he calls the fields. He describes our social position in society or our position in a field affecting the forms of capital we have. The forms of capital are economic, social, symbolic, and cultural. Social capital is generally the value and or resources that can be generated by social networking. Cultural capital refers to quality and 
objects beyond the economic capital that allows one to do so. Progress in society such as education, physical appearance, style of dress, and so forth. Actually, being an UGM student is a form of capital in society because to enter UGM students is certainly not easy. However, just being an UGM student is not enough to be able to join this club, it takes a minimum of capital, cultural capital, and economic capital to follow the rhythm within the club. Symbolic capital is obtained individually, and, in some contexts, some people are considered more valuable than others. Social networks, norms, values, tastes, economics, education, physical appearance, and achievement is the ability to form the self, and they contribute to what Bourdieu (1978) refers to as the habitus. A habitus organizing and directing this social action is a set of internalized and internalized dispositions that shape the individual's sense of self towards their character, perception, and taste character (Gilbert \& Gillett, 2012, pp. 632-643; Bourdieu, 1978, pp. 819-840; Kay \& Laberge, 2002, pp. 17-36).

Hanif Mufti (21), the head of the UGM Equestrian Unit in the period of 2016 said that his activities had been fully supported by his parents. He has his own horse inside the club, but at the time of the research, his horse is being sent to Bogor to be trained, he said that: If a good horse like that, it depends on the needs of each and its level. It cannot be equated, a horse to equestrian with racehorses, they totally different. Meanwhile, with close proximity, I interviewed Yuliana, (20) a senior member of the jumping field from Biology faculty telling me that her parents even still thought her daughter follows a horse racing club and not an equestrian. Obviously, Hanif and Yuliana's habitus are different, but they are put together in a club, but still, I feel that they will get an unequal position in the arena. Since there are many new members coming in from various circles within the arena each year, a competitive mechanism is created, with Bordieu (1984, pp. 130-232) I see it as a distinction to see the habitus and capital by creating an internal competition that compares the jumping and dressage categories. Achieving members certainly have capital of cultural capital, economy, and of course symbolic capital. It became an unwritten convention for new members to be able to occupy important positions within the club when they became a senior member.

At the time of the practising, I observed that they formed certain gang patterns that were sometimes very clear to see. There are gangs that taking care for horses that willing to get dirty, there are also elitist hordes not involved too far in taking care of horses and keep the body clean. They stand inside a club together, but in reality, they stand separately. At the end of each semester, an internal competition mechanism is created. I see it as a way to see the habitus and capital of each member by creating an internal competition that compares the jumping and dressage categories. They compete with complete fashion and are shown to the public. Stand out members certainly have cultural capital, economic capital and of course symbolic capital. It became an unwritten convention for new members to be able to occupy important positions within the club when they became a senior member. Those who are not able to follow will be marginalized by themselves. So that new members who are heterogeneous at the end of the year will be separated according to their respective resilience. Once filtered, they recruits new members to join the club again, to be processed and to be sorted again at the end of the year, and so on.

\section{For the Intruders, Technology Bless}

Pierre Bourdieu (1984, pp. 130-232) explains that agents, human or non-human, and their social position are located and can be seen in a field. An agent's social position is influenced by the interaction between field rules (in this case equestrian sport) and his agent. There is a phenomenon of breaking through the class through this gap. The concept of capital and habitus determines the social position in the field and this is interesting because the members of UGM Equestrian Unit are not from the same background. I call them the intruders. At least students of the middle classes and working classes can join. In Fletcher and Dashper, I see the overview of an article analyzed in another Giles Coran in The Times (10 August) complaining about the audience's indifference to the uninitiated, and stressing the lack of sports spectacle:

I have no idea at all what is going on. I applaud it. I am all for it. Lovely-looking gee-gees. Hats off to the guys and girls in top hats and morning coats ... But as a sporting spectacle, this is truly the least exciting thing I have ever seen"(The Sun 6 August).

Interestingly, this phenomenon also occurs in the riding environment in Yogyakarta. When the game is always crowded with the audience, based on my interview with the audience in internal 2016 matches, they (the spectators off the field) do not know what is actually contested, except on the jumping session. This confusion is a good gap for class breakers to move vertically. In my interview with the head of the club, I asked why at the time of practice they always carry a camera which is then used interchangeably. He 
replied, "It is ordinary, they take photos when they train, and they upload it usually, especially at the internal championship". So, I think that technology (photo and social media) can help a person emulate or mimicry a particular class and then display it in social media because visual speaks louder on social media, technology blessing. What is interesting is the tendency of female enthusiasts UGM Equestria Club also continues to rise year by year. So, I can say that what I say as the intruders in UGM Equestrian Unit is mostly female. Indeed, after I became acquainted with all members of the $26^{\text {th }}$ generation of $2016 \mathrm{I}$ observed and opened their social media, especially Instagram account, and the result is $100 \%$ of the members of the club have uploaded a photo with the horse with $80 \%$ ratio used as a profile photo.

\section{Conclusions}

Because it retains an image of tradition and conservatism (Dashper, 2012c, pp. 213-225). There is no doubt that UGM equestrian unit is a leisure choice for students at UGM, although the club is trying to portray itself as a friendly sport for a student from all social classes. Referring to Bourdieu (1984, pp. 130-232) actually, being an UGM student is a form of distinction society because to enter UGM students is not easy. However, being an UGM student is not enough to be able to join this club, it takes a minimum of capital culture capital and economic capital to follow the rhythm within the club. Funds are trimmed as affordable to prospective members. This opportunity is an opportunity for prospective members of the middle and working class to enter and try to break through the class. Trending through this class is actually happening in the millennial digital community, they just need to log in briefly and then upload the photos to be acknowledged by their 'followers'. I call them 'the intruders'. Due to the fact, when already joined the club there will be many unwritten needs that must be met from the cost of horse care, equipment to fashion used. Stumbling members (especially 'the intruder') will be marginalized and the conqueror will survive. This phenomenon is seen in the first half after recruitment is a lot of intruders who then detached or inactive. For the people outside their club (the audience) (either 'the intruder' or not) looks the same as an equal class society. But inside a club is an arena, within a club, an object can cause a member to receive symbolic violence when not wearing it. Because there are many new members who enter from various circles within the arena in each year, a championship mechanism is created to view the habitus and capital by creating an internal competition that compares the jumping and dressage categories. I see it as a distinction to see the habitus and capital by creating an internal competition that compares the jumping and dressage categories. Achieving members certainly have capital of cultural capital, economy and of course symbolic capital. It became an unwritten convention for new members to be able to occupy important positions within the club when they became a senior member. Simply put, it's like giving the widest possible opportunity (especially students from working-class and middle-class families) to taste the upper-class sports at the beginning of the semester and then sorting, purifying and refining them at the end of the year. This is what makes the UGM equestrian unit as an 'upper-class' student activities appear even stronger, reproduced and never changed year after year.

\section{References}

Bourdieu, P. (1984). Distinction: A social critique of the judgement of taste. Cambridge, MA: Harvard University Press.

Bourdieu, P. (1978). Sport and social class. Theory and methods, 17(6), pp. 819-840.

Dashper, K. (2012a). The Olympic experience from a distance: The case of the equestrian events at the 2008 games. In Shipway, R. \& Fyall, A. (Eds.), International sports events: Impacts, experiences and identities (pp. 213-225).

Dashper, K. (2012b). 'Dressage is full of queens!' Masculinity and Sexuality within Equestrian Sport. Sociology (pp. 1109-1124).

Dashper, K. (2012c). Together, yet still not equal? Sex integration in equestrian sport. Asia-Pacific Journal of Health, Sport and Physical Education 3(3), 213-225. 
Fletcher, T., \& Dashper, K. (2012). Bring on the dancing horses!': Ambivalence and class obsession within British media reports of the dressage at the London 2012 Olympic games. Sociological Research Online, $18(2), 1-3$.

Gerke, S. (2000). 'Global lifestyles under local conditions: The new indonesian middle class'. In Beng-Huat Chua (Eds.), Consumption in Asia: Lifestyles and identities, (pp. 146-151).

Gilbert, M., \& Gillett, J. (2012). Equine athletes and interspecies sport. International Review for the Sociology of Sport, 47(5), 632-643.

Gilbert, M. (2013). Young equestrians: The horse stable as a cultural space. In J. Gillett \& M. Gilbert (Eds.), Sport, Animals, and Society. (pp. 233-250). NewYork: Routledge.

Gilbert, M., \& Gillett, J. (2013). Women in equestrian polo: Cultural capital and sport trajectories. Gender and Equestrian Sport. (pp. 111-125). Springer Netherlands.

Gymnastiar, A. (2016). Hikmah olahraga memanah dan berkuda (The wisdom of archery and riding). CV. Smart Tauhiid: Bandung. (pp. 1-17). [In Bahasa Indonesia].

Kay, J., \& Laberge, S. (2002). The 'new' corporate habitus in adventure racing. [International Review for the Sociology of Sport], 37(1), 17-36.

Locker, M. (2012, August 15). Watch: PSY's 'Gangnam style' is the best invisible horse-riding rap video you'll see all week. Time.

Polley, M. (1999). Moving the goalposts: A history of sport and society since 1945. London: Routledge. (pp. 200-236).

Pyke, K. D. (1996). 'Class-based masculinities: The interdependence of gender, class, and interpersonal power', Gender and Society, 10(5), 527-549.

Riedi, E. (2006). Brains or polo? Equestrian sport, army reform and the 'gentlemanly officer tradition': 1900-1914. Journal for the Society of Army Historical Research 84, 236-253.

Sugden, J., \& Tomlinson, A. (2000). Theorizing sport, social class and status. In J. Coakley \& E. Dunning (Eds.), Handbook of Sports Studies. 311. Oxford: Sage.

Veblen, T. (2000[1899]). The theory of the leisure class. New Jersey: Transaction. (pp. 69-94). 